\title{
Tissue doppler imaging in cardiology nowadays: clinical applications
}

\author{
Antoine Kossaify* \\ Head of Electrophysiology Lab, University Hospital N Dame de Secours, Lebanon
}

\section{Introduction}

Tissue Doppler Imaging (TDI) has made a long way in Echocardiography since the first investigations on tissue characterization and cardiac tissue motion were documented; indices on deformation imaging (scattering characteristics, tissue motion and velocity) were evoked in investigational studies more than 20 years ago $[1,2]$.

TDI measures myocardial velocity and velocity gradient, which are indirect indices of myocardial deformation whereas strain imaging is a more sensitive technique for quantifying regional myocardial deformation. Besides being a more sensitive technique and angle independent, strain imaging allows early detection of many subclinical myocardial diseases such as idiopathic dilated cardiopathy. However, TDI has a higher temporal resolution than strain imaging, it is a less time consuming technique and it has specific and relevant clinical applications: assessment of diastolic dysfunction, assessment of left ventricular $(L V)$ and right ventricular $(R V)$ systolic function, evaluation of ventricular dyssynchrony, assessment of constriction versus restriction. In addition, TDI has other uses in today echocardiography, like study of left atrial mechanics and prediction of myocardial viability, though these advanced techniques are not commonly used in every day practice.

\section{Assessment of diastolic function}

The latest guidelines on diastolic function study focus on TDI both for diagnosis and grading of diastolic dysfunction [3]. According to these guidelines, evaluation of diastolic function could not be made without TDI; among the 5 parameters used for diagnosis of diastolic dysfunction, TDI parameters comprise 3 of them (early diastolic septal velocity, medial E'; early diastolic lateral wall velocity, lateral E'; E/E'). Of note, acquisition of E' is made via spectral TDI, and it is feasible with relatively high relevance even when sonographic signal is poor. However, a good alignment is a pre-requisite in order to avoid underestimation of $\mathrm{E}^{\prime}$ value, given that TDI is an angle-dependent technique. TDI for assessment of diastolic function is a routine test in every day echocardiography, however it is particularly important for patients with preserved ejection fraction heart failure and for evaluation of LV filling pressure.

\section{Assessment of systolic function}

The most commonly used parameter is longitudinal septal systolic velocity (Sm) for LV systolic function and it is acquired as for E' with the same spectral TDI mode. As for the E' acquisition, Sm acquisition is relatively feasible even when sonographic signal is relatively poor, however a good alignment is necessary given the angle-dependency. For the RV, TDI is used usually in conjunction with TAPSE (tricuspid annulus plane systolic excursion) at the level of basal RV free wall; contrary to the Sm value, TDI of the lateral RV free wall is indicative of the global RV function and not only local wall motion [4]. TDI assessment of LV systolic function is particularly important in subclinical LV systolic dysfunction given that $\mathrm{Sm}$ showed to be a sensitive marker of early LV systolic dysfunction.

\section{Assessment of synchrony}

Whether at the level of intraventricular or interventricular motion, TDI with its high temporal resolution allows a sensitive estimation of all synchronization parameters. Of note, color TDI is a qualitative technique that allows visual estimation of synchrony, using different coded colors that may be translated into curves (semi-quantitative technique) showing the earliest and latest segment contraction. Moreover spectral TDI is useful for tissue synchronization studies, and commonly used parameters are "time to onset" (from beginning of QRS to onset of systolic motion on spectral curve), "time to peak" (from onset to peak of motion on spectral curve). Ventricular synchrony study is particularly useful for patients with systolic dysfunction and wide QRS for whom resynchronization therapy is evoked, also it has a prognostic value during the follow-up of patients with a cardiac resynchronization device [5].

\section{Assessment of constriction and restriction}

TDI is a valuable method to differentiate restrictive cardiomyopathy from constrictive pericarditis. Values of septal E' above $8 \mathrm{~cm} / \mathrm{s}$ strongly favor the diagnosis of constriction while values less than $6 \mathrm{~cm} / \mathrm{s}$ favor constriction. Values of medial E' $\geq 6$ and $\leq 8$ may represent mixed constriction and restriction, and therefore additional parameters may help to clear the situation: annulus reversus (medial E' > lateral E') and hepatic veins expiratory end-diastolic reversal velocity strongly suggest constriction [3].

\section{Other uses of TDI}

Many other uses of TDI have been suggested, namely to assess left atrial mechanics and risk of supraventricular arrhythmia [6,7]. Moreover, TDI coupled with strain rate imaging helps to assess myocardial function and viability in ischemic cardiomyopathy;

Correspondence to: Antoine Kossaify, MD, Cardiologist, Associate Professor, Head of Electrophysiology Lab, University Hospital N Dame de Secours, Head of Research Department, USEK school of Medicine, Tel: +9613232192 - Byblos, Jbeil, Lebanon

Received: February 18, 2017; Accepted: March 11, 2017; Published: March 13, 2017 
however, strain imaging is more sensitive in these indications given its angle independency and its higher spatial resolution [8].

\section{Conclusion}

TDI is a relatively simple echographic modality, relevant even when sonographic signal is moderate, and has special applications in many cardiovascular conditions like assessment of diastolic function, systolic longitudinal LV and global systolic RV function, inter- and intraventricular synchrony, constriction and restriction.

\section{References}

1. Taylor KJ, Wells PN (1989) Tissue characterisation. Ultrasound Med Biol15: 421-428. [Crossref]

2. Fleming AD1, McDicken WN, Sutherland GR, Hoskins PR (1994) Assessment of colour Doppler tissue imaging using test-phantoms. Ultrasound Med Biol20: 937-951. [Crossref]

3. Nagueh SF, Smiseth OA, Appleton CP, Byrd BF, $3^{\text {rd }}$, Dokainish H, et al. (2016) Recommendations for the Evaluation of Left Ventricular Diastolic Function by
Echocardiography: An Update from the American Society of Echocardiography and the European Association of Cardiovascular Imaging. J Am SocEchocardiogr 29:277314.[Crossref]

4. Kossaify A, Grollier G (2014) Echocardiography practice: insights into appropriate clinical use, technical competence and quality improvement program. Clin Med Insights Cardiol8:1-7.[Crossref]

5. Tayal B, Gorcsan J 3rd, Delgado-Montero A, Marek JJ, Haugaa KH, et al. (2015) Mechanical Dyssynchrony by Tissue Doppler Cross-Correlation is Associated with Risk for Complex Ventricular Arrhythmias after Cardiac Resynchronization Therapy. $J$ Am SocEchocardiogr28:1474-81. [Croossref]

6. Leischik R, Littwitz H, Dworrak B (2015) Echocardiographic Evaluation of Left Atrial Mechanics: Function, History, Novel Techniques, Advantages, and Pitfalls. Biomed Res $\operatorname{Int} 765921$. [Crossref]

7. Kallenberger SM, Schmid C, Wiedmann F, Mereles D, Katus HA, et al. (2016) A Simple, Non-Invasive Score to Predict Paroxysmal Atrial Fibrillation. PLoS One 11: e0163621.[Crossref]

8. Thibault H, Derumeaux G (2008) Assessment of myocardial ischemia and viability using tissue Doppler and deformation imaging: the lessons from the experimental studies. Arch Cardiovasc Dis 101:61-8. [Crossref]

Copyright: $\odot 2017$ Kossaify A. This is an open-access article distributed under the terms of the Creative Commons Attribution License, which permits unrestricted use, distribution, and reproduction in any medium, provided the original author and source are credited. 